\title{
Modified Screw Jack for Lifting Operation in Industrial Setting
}

\author{
Benjamin Ezurike ${ }^{1 a^{*}}$, Modestus Okwu ${ }^{2 b}$ \\ ${ }^{1}$ Department of Mechanical Engineering, Madonna University, Nigeria \\ ${ }^{2}$ Department of Mechanical Engineering, Federal University of Petroleum Resources Effurun, \\ Nigeria. \\ a*ben4oke2000@yahoo.com; ${ }^{*}$ mechanicalmodestus@yahoo.com
}

Keywords: Scissor jack; gear arrangements; quick lifting; gear mechanism

\begin{abstract}
With the increasing level of technology, researchers all over the world are working continuously to improve and implement better and robust design of materials at workplace for productivity, efficiency and effectiveness. Detailed design procedure of a quick lifting screw jack is presented in this paper. The design is fundamentally a modification of the conventional scissor jack. The problems associated with the conventional jacks are the ergonomic snags experienced by operators due to prolonged bending or squatting positions during operation. These problems of waist pain and backaches are as a result of continuous turning of the wrench or crank shaft in an uncomfortable position for a long period. These led to the design and modification of quick lifting screw jack with gear arrangements that are safe, reliable and capable of raising or lowering heavy load with little effort. The results showed that the introduction of the crank and gear mechanism would help reduce difficulty in operation, reduce time, increase efficiency and effectively control the difficulties concomitant with Ergonomics - which is an ultimate sensitivity in design process.
\end{abstract}

\section{Introduction}

Over the years, engineers, scientist and ergonomist have extolled the conventional automobile screw jack (scissors jack) as being very efficient, yet continue to seek new designs to increase reliability and reduce its shortcomings and maintenance costs. Screw application is used in the elevation of vehicles or objects. The operation of the screw jack is such that it comprises a handle for driving a bolt element (Lead Screw) manually to adjust the height of the jack to elevate a vehicle or an object. Existing jacks are of great disadvantage to elderly women especially under unfavorable weather condition [1]. A mechanical jack is a device which lifts weighty or heavy equipment and vehicles so that maintenance can be carried out underneath at workplace or manufacturing setting [2]. A jack screw is a type of jack which functions by turning a lead screw. It is commonly used to lift heavy load to a height. A good example is the car-jacks. In the case of a screw jack, a small force applied in the horizontal plane is used to raise or lower large load [3]. A good number of operational staff in manufacturing, bottling, oil and gas and other multi-national companies perform task in a squatting or cowering position for a long period. These results to inefficiency at workplace due to ergonomically imbalance position they encounter which often times give rise to back ache and poor body architecture in the future.

These present available jacks further require the operator to remain in prolonged bent or squatting position to operate the jack. Due to its difficulties, body pains, back ache and others can emerge as a result of continuous turning of the wrench or crank shaft in an uncomfortable position for a long period. The statement of problem has led to the motivation of designing a modified quick lifting screw jack with gear arrangement. The introduction of the bevel gear will help reduce difficulty in operation with a handle incorporated in the design and also reduce time spent to a very minimum.

\subsection{Screw Jack and Types}

Automobile screw jacks or jack screw is a device that is used to lift an automobile in order to carry out repairs or maintenance. Screw jacks are designed with materials having the capabilities and properties to lift heavy loads and prevent buckling, wear etc. which can result to unforeseen 
accidents. Screw jacks have been used for more than 50 decades with new developments and redesigns [3]. The conventional screw jack (which is the scissors jack) is still commonly used due to its many advantages such as long life span, strength, packaging, mobility, cost etc., with the greatest to be its self-locking attribute, which means when the rotational force on the screw is removed, it will remain motionless where it was left and will not rotate backwards, regardless of how much load it is supporting. This makes them inherently safer than hydraulic jacks, for example, which will move backwards under load if the force on the hydraulic actuator is accidentally released. Mechanical advantage is important in car jacks because it enable human lift a vehicle by manual force single-handedly. More powerful jacks use hydraulic power to provide more lift over greater distances. Mechanical jacks are usually rated for maximum lifting capacity. This is peculiar in developing nations where traditional screw jacks are often in use. $[4,5]$ designed and fabricated a motorized automated object lifting jack using electric motor for lifting and lowering of heavy loads. The electricity for the operating the jack was from the direct current (dc) battery with increased mechanical advantage. Okoronkwo et al. [6] developed hand water pump using quick return crank mechanism. Chaudhary et al. [7] designed a screw jack using solid works 2010, after the design, they constructed the jack using available machine tools like: lathe, grinding, threading and milling machines. The developed jack was tested and found effective in addressing ergonomics issues. Kumar et al. [8] designed and constructed screw jack by taking into consideration worm and spur gear arrangement. The component part that makes up the developed system consist of the worm gear, spur gear, ball bearings and circular shafts. They considered soft engineering materials in the development of the worm gear. The materials taken into consideration include alloys of metal like aluminum and bronze. In the design of the lifting screw they considered a tough and heat treated hard material and also performed failure analysis in considering the appropriate screw shaft.

There are different kinds of jacks available; a good example is the bumper jacks obtainable in older cars and scissor jacks, quite common in newer cars. The tension force applied by the jack lead screw gives rise to a compressive force. An Acme thread is a very tough and strong thread often used and is capable of resisting the large loads imposed on most jack screws. Car jacks usually use mechanical advantage to enable vehicle lifting. There are two types of automotive car jacks: Hydraulic and Screw type. The screw type is common. The screw-type devices has a very great advantage which has to do with the tapered sides of the screw wear, the mating nut automatically comes into closer meeting, instead of allowing backlash to develop [9]. There are also categories of screw and hydraulic jacks. Hydraulic jacks have a bottle shape. By operating the handle, which is a lever (a simple machine), fluid is compressed and routed to an actuating cylinder which results in lift. Other examples of hydraulic type of screw are hydraulic jack, bottle jack, floor jack, friction jack, and racketing jack. Parker and Pickup [10] revealed the accurate and precise prognostication of a screw thread, the tedious nature and time taken to achieve the lifting process. Different design of threads are shown conventionally on engineering drawings. It is also very important to note the need to lubricate screw jacks with grease on regular basis. Another type of screw is the ball screw which is quite unconventional and uses recirculation-ball nut to minimize friction and prolong the life of the screw threads. The major disadvantage of this kind of ball screw is its inability to selflock [11]. Attention of researchers has been drawn to the failure of screw in manufacturing and production companies. The major causes of screw failure is attributed to poor design, lack of grease and poor engineering practices [12]. 

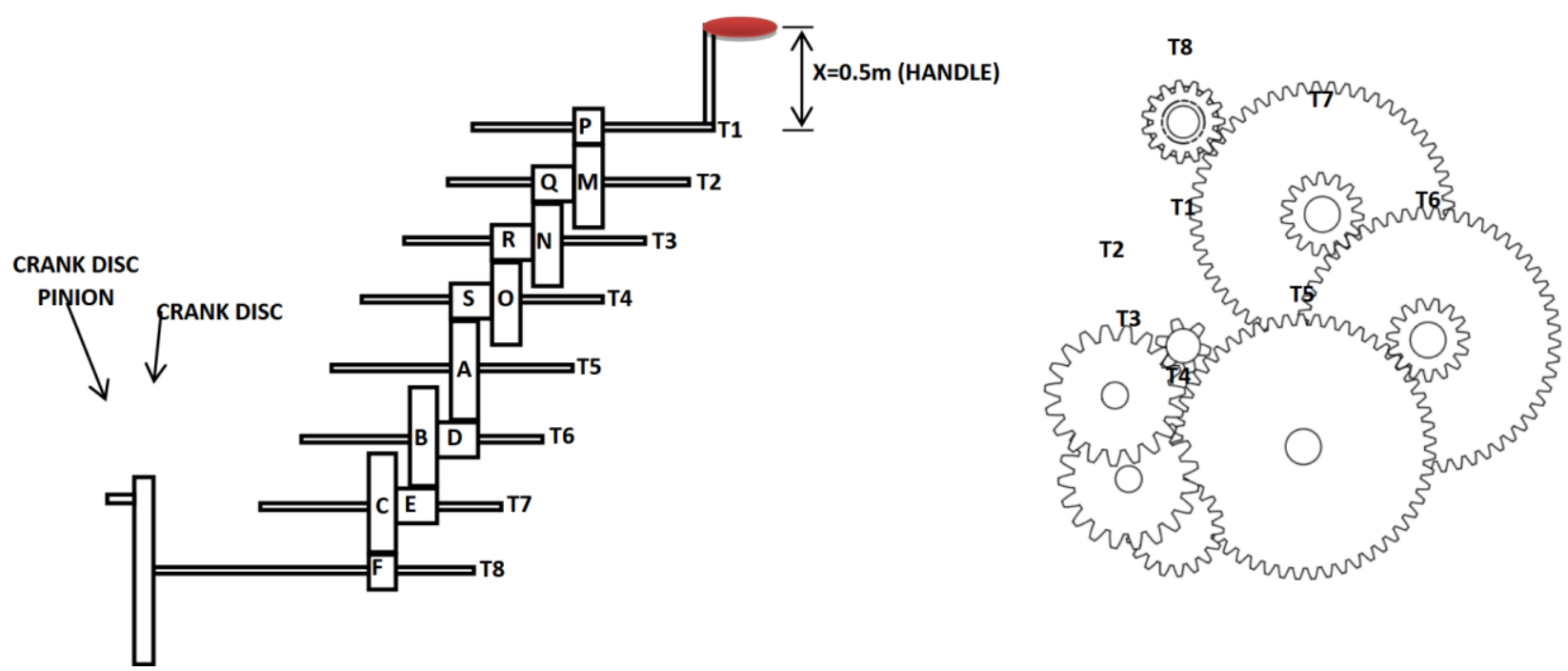

Figure 1. Detailed view of gear drive arrangement in proposed design.

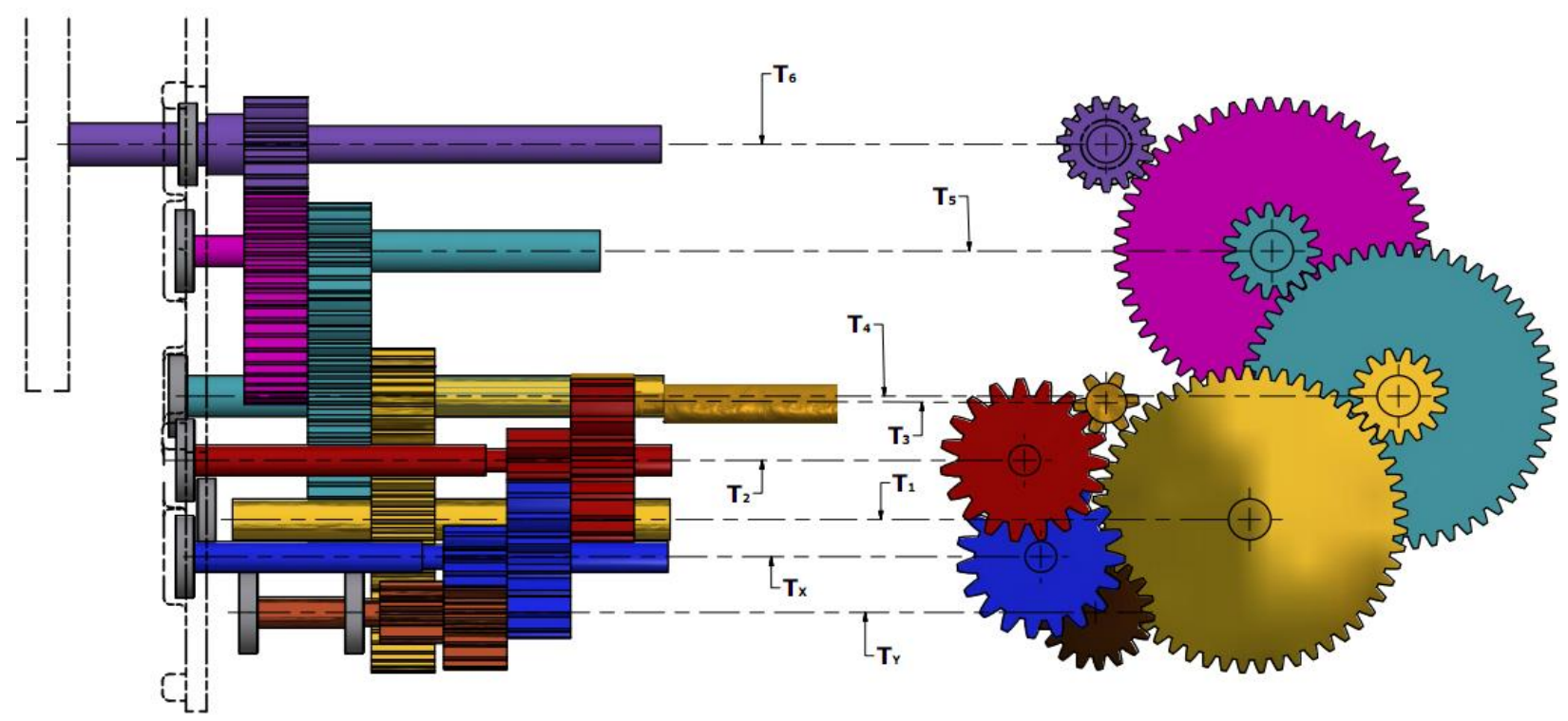

Figure 2. Gear drive arrangement in proposed design.

\subsection{Principle of Operation}

During usage, the screw jack is assembled for operation with Fig. 7 extended properly. The jack is then placed perfectly under the vehicle with Fig. 2 loading platform serving as a base for support. Fig. 4, functions as the effort that aids rotation of Fig. 3. During the process of lifting Fig. 4 rotates in clockwise direction allowing Fig.3 rotate as well (engaging gearing motion) which aids in the upward movement of Fig. 2. The reverse is the case when Fig. 4 is turned counter clockwise, allowing downward movement of Fig. 3 thereby lowering the load. Doing all these like the conventional screw jack (scissors jack), the operator must carefully inspect the operation making sure the load sits perfectly on the loading platform to prevent unsafe conditions i.e. slippage of the vehicle from the jack. 


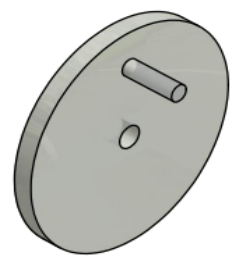

ISOMETRIC

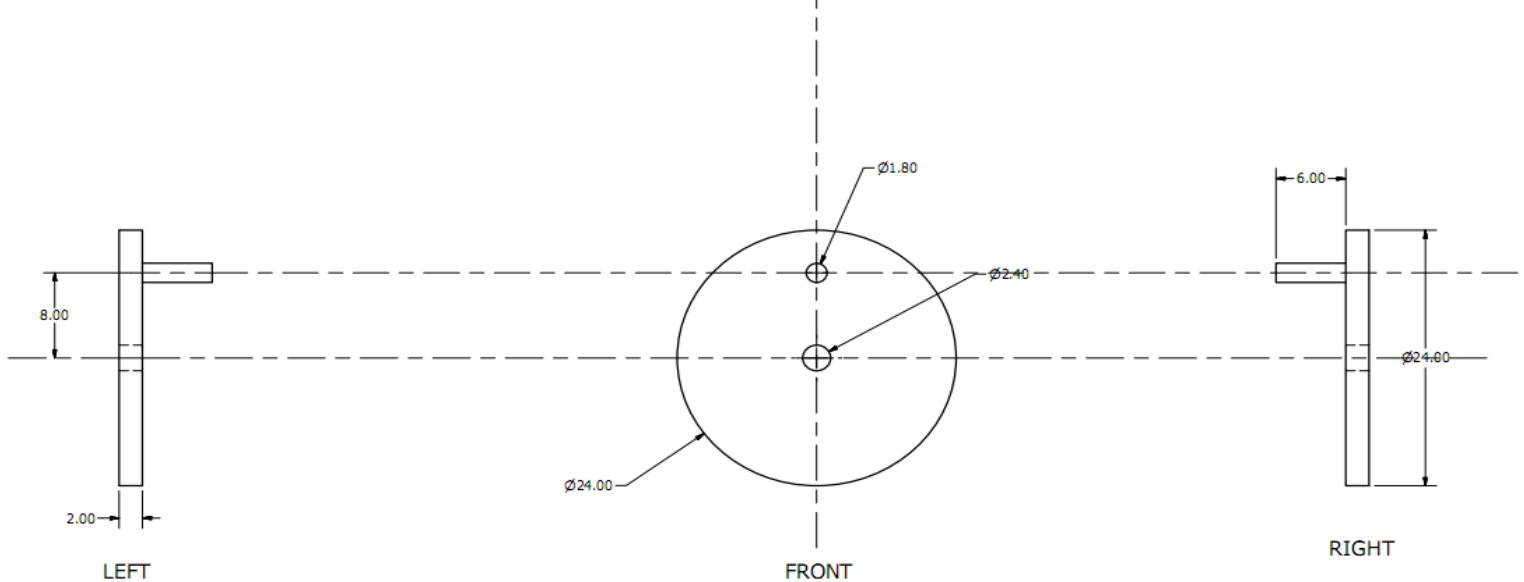

Figure 3a. Crank disc and crank disc pinion.

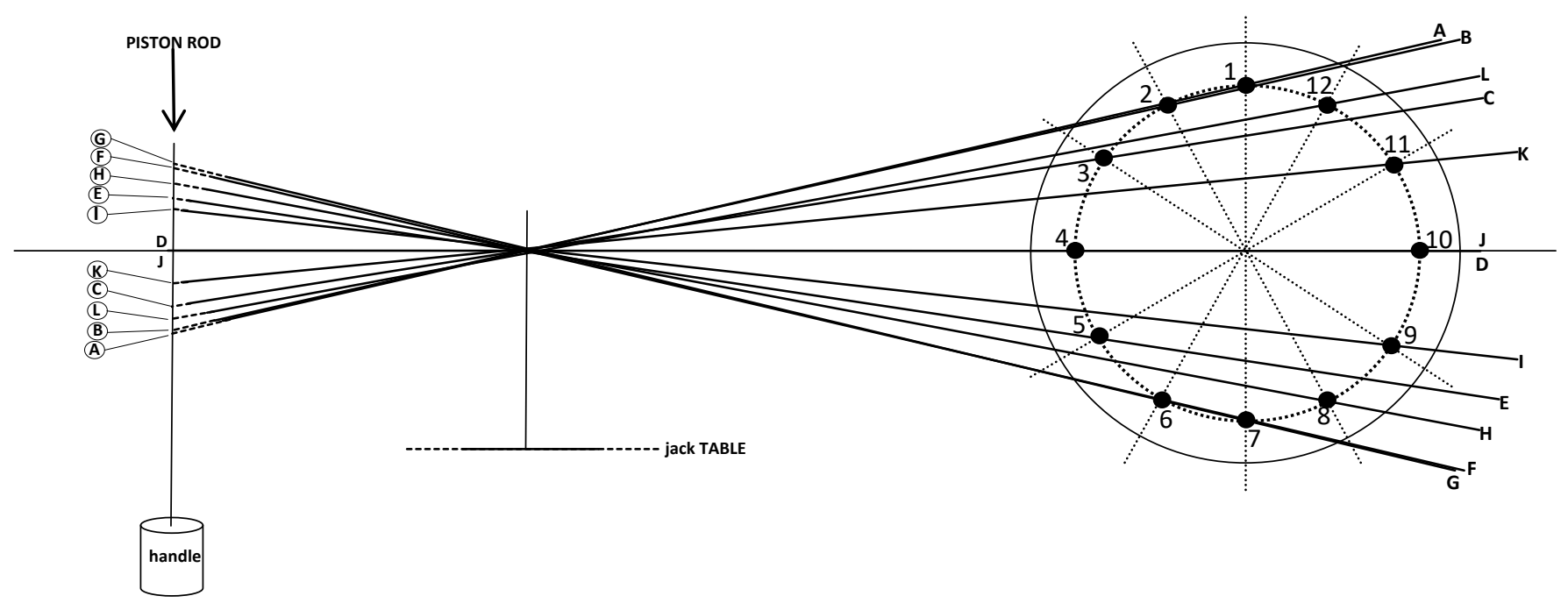

Figure 3b. Quick-return crank mechanism showing crank disc pinion positions along its path profile and relative to crank beam positions and piston rod attachment point path profile. [6]

\section{Design Analysis and Calculation}

\section{Material Selection of Parts:}

The choice of material is very important in the design of an automobile jack as in the case of other engineering designs. It is one of the most important decisions a designer is called to make. The decision is usually made before the dimensions of the part are established. One very important factor in material selection is the strength. Other factors include wear, corrosion, weight, noise, lubrication, marketability, manufacturability, safety, functionality, cost, etc. Some aforementioned have to do unswervingly with the dimensions, the material, the processing, and the joining of the element of the system. For effective performance of jack, mild steel is majorly used because of its strength, toughness and low cost. It provides material properties that are acceptable for the application. Finally, the selected material of mild steel gives a reduced weight of the jack. 


\section{Computational Tools:}

Computer-aided design (CAD) software allows the development of three-dimensional (3-d) design from which conventional two-dimensional (2-d) orthographic views with automatic measurement can be produced. The CAD software package used for this project is Solid works 2015, which allows rapid and accurate modeling, calculation of mass properties, location of center of gravity, 2-d and 3-d views etc., with lots of material selections for parts or member.

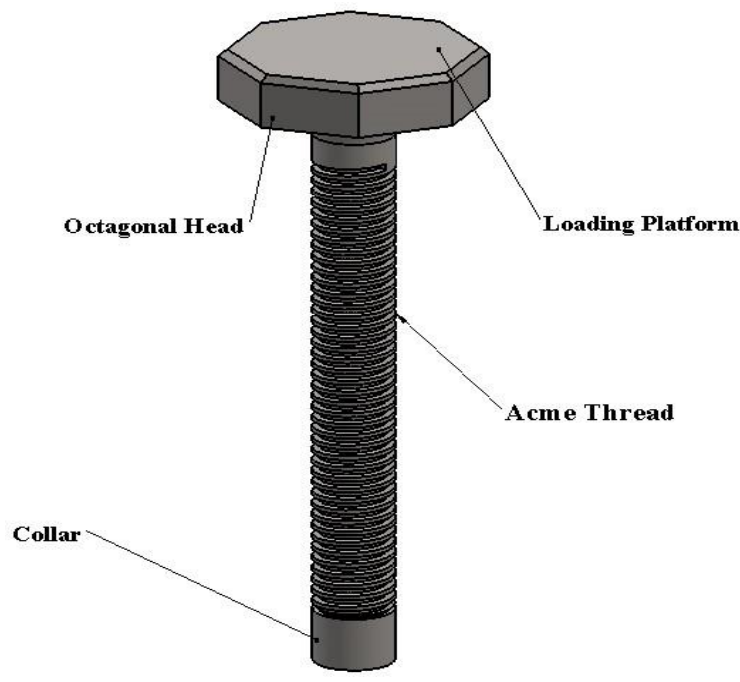

Figure 4. Power screw.

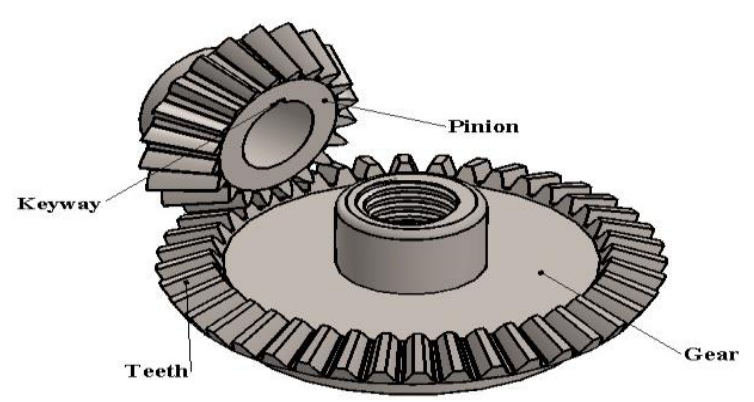

Figure 5. Bevel gear.
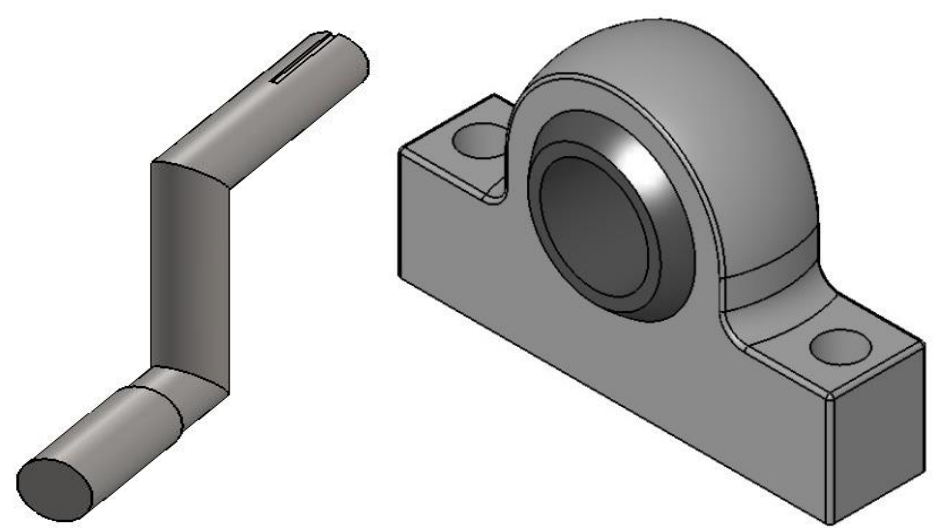

Figure 6. Crank Handle.

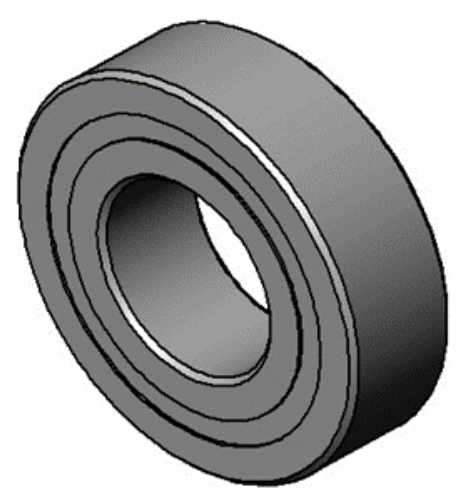

Figure 7. Bearings. 


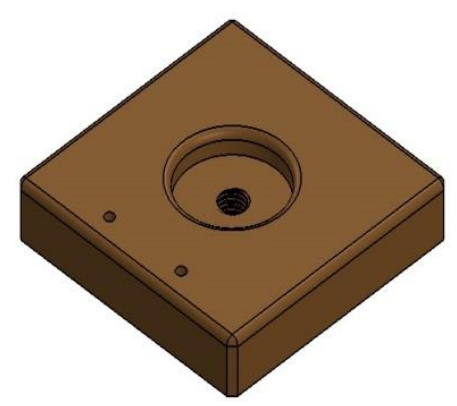

Figure 8. Jack frame.

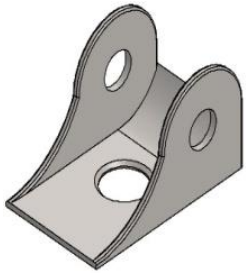

Figure 10. Bracket.

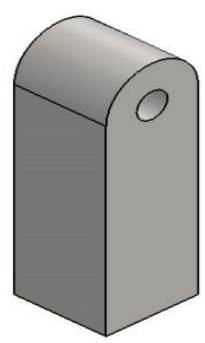

Figure 9. Stand.

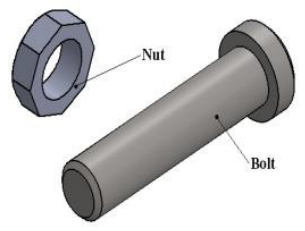

Figure 11. Bolt and Nut.

\subsection{General Design Calculations}

\subsubsection{Determination of a Velocity Ratio}

Velocity ratio of gears can be calculated using Equation 1 as given by [13]:

$$
V R=\frac{N}{n}=\frac{t}{T}
$$

where, $\mathrm{N}=$ Number of revolutions of driver gear, $\mathrm{n}=$ Number of revolutions of driven gear, $\mathrm{T}=$ Number of teeth of driver gear, $\mathrm{t}=$ Number of teeth of driven gear

\subsubsection{Determination of Gear Parameters}

Allowable tooth stress can be calculated by Equation 3.5, given by [14]:

$$
S_{a}=S_{o}\left(\frac{3}{3+V}\right),
$$

where $S_{o}=$ Endurance strength, V= Pitch line velocity, and V $<10 \mathrm{~m} / \mathrm{s}$.

Bending stress or permissible working stress (б) in the tooth can be calculated by Equation 3.

$$
\sigma=\frac{\left(W_{T}^{*} h\right)^{* 6}}{b^{*} t^{2}},
$$

where $\mathrm{W}_{\mathrm{T}}=$ Tangential load acting on the tooth, $\mathrm{h}=$ Length of the tooth, $\mathrm{b}=$ Width of gear face, $\mathrm{t}=$ Tooth thickness.

Dynamic tooth load can be calculated using Equation 4 also given by [15];

$$
F_{d}=\frac{21 V(b c+F)}{21 V+\sqrt{b c+F}}+F
$$

where $\mathrm{V}=$ Pitch line velocity, $\mathrm{b}=$ Face width, $\mathrm{C}=$ Constant which depends on the tooth form, material and degree of accuracy with which the tooth is cut, $\mathrm{F}=$ Force or Tangential load acting on the tooth.

Force above can be calculated by using Equation 5

$$
F=\frac{2 M_{t}}{D},
$$


where $\mathrm{M}_{\mathrm{t}}=$ Gear torque, $\mathrm{D}=$ Pitch diameter of gear.

Wear tooth load is given by Equation 6

$$
F_{w}=D_{p} b k Q
$$

where $D_{p}=$ Pitch of smaller gear (pinion), $b=$ Face width of gear, $K=$ Stress factor of fatigue, $\mathrm{Q}=$ Gear factor.

Gear factor in Equation 6 can also be calculated, using the Equation 7

$$
Q=\frac{2 N_{g}}{N_{p}+N_{g}},
$$

where $\mathrm{N}_{\mathrm{g}}=$ Number of teeth on gear, $\mathrm{N}_{\mathrm{p}}=$ Number of teeth on pinion.

In design of conventional conventional lifting jacks, the total force required to lift the piston during the upward stroke is equal to the sum of the following [13]

$$
F_{L}=F_{P}+F_{r}+F_{W},
$$

where $F_{p}=$ Force due to the weight of the piston, $F_{r}=$ Force due to the weight of the piston rod, $\mathrm{F}_{\mathrm{w}}=$ Force due to the weight of the vehicle having a cross-section equal to that of the jack.

Piston weight and the piston rod weight are due to the inertia force. Therefore, the stepwise evaluation of these forces is presented. Since the piston weight and piston rod weight possess mass, the inertia force acting on them must be evaluated. Generally, inertia force is a product of mass and acceleration .Therefore, the inertia force due to the piston is obtained by multiplying the mass of the piston by the acceleration. Thus, the inertia force of the piston is given as:

$$
F_{\text {inertia }}=M_{w} a_{\text {piston }} .
$$

But the acceleration of the piston can be evaluated using the expression giving by [14]

$$
a_{p . \max }=\frac{-\omega^{2} S}{2},
$$

where $\mathrm{S}=$ Piston stroke, $\omega=$ Angular velocity of the driving the driving crank.

Power required to drive the gear train can be calculated using [13]:

$$
H=\frac{T}{\eta_{g}} \omega=\frac{D_{g}}{2} \omega \frac{W_{t}}{\eta_{g}}=F_{L} S \frac{N}{\eta_{g} 60} W,
$$

where, $\eta_{\mathrm{g}}=$ Gear drive efficiency.

In conventional lifting jack designs, the ratio $\mathbf{F}_{\mathbf{W}} \mathbf{F} \mathbf{F i}_{\mathbf{P}}$ is usually large so that $\mathbf{F i}_{\mathbf{P}}$ can be assumed negligible. Also, the force due to weight of piston rod is usually small compared to that, due to the weight of the vehicle.

$$
\eta_{m a} W_{a}=\frac{\pi}{4} d^{2} c \rho_{W} g H_{s t},
$$

where $\eta_{m a}=$ The mechanical advantage, $\mathrm{W}_{\mathrm{a}}=$ Allowable maximum load for users, $\mathrm{R}=$ Power input through the crank handle, $\mathrm{R}=$ Crank radius.

\subsubsection{Determination for Design of Power Screw}

In designing an acme thread power screw for jack operation, the screw must be self-locking and have strength to prevent buckling and safe enough to prevent harm. The coefficient of friction in screw thread is independent of axial load, practically independent of speed, decreases with heavier lubricants, show little variation with combination of materials. The screw also should have a safe bearing pressure $(\mathrm{Pb})$ on threads to protect the moving surfaces from abnormal wear. For safe 
bearing pressure, $\mathrm{Pb}=17.2-24.1 \mathrm{MPa}$. Coefficient of friction $=0.15-0.23$ for steel because the material is known under reasonably constant service conditions subjected to loads and stresses that can be determined easily. [13].

To check for safety of lead screw, compressive stress induced in the screw due to load is given as follow:

$$
F_{c}=\frac{W}{\frac{\pi}{4} d_{c}^{2}}
$$

Therefore,

$$
\text { factor of safety } \quad=\frac{\text { yieldstress }}{F_{c}} .
$$

For the screw to be safe in tension,

$$
d_{c}=\sqrt{\frac{p^{*} 4}{\pi^{*} \sigma_{t}}},
$$

where $\mathrm{P}=$ Pitch, $\mathrm{d}_{\mathrm{c}}=$ core diameter of screw, $\mathrm{d}_{\mathrm{m}}=$ mean diameter, $\mathrm{F}_{\mathrm{c}}=$ compressive stress, $\mathrm{W}=$ load, $\mathrm{Y}=$ yield stress obtained from the material properties of the screw, $\sigma_{t}=$ tensile stress.

Outside diameter of screw,

$$
\mathrm{d}_{\mathrm{o}}=\mathrm{d}_{\mathrm{c}}+\mathrm{P} \text {. }
$$

Mean diameter of screw,

$$
\left(d_{m}\right) \quad d_{m}=\frac{1}{2}\left(d_{c}+d_{o}\right)
$$

Helix angle of screw $(\alpha)$,

$$
\alpha=\tan ^{-1}\left(\frac{p}{\pi d_{m}}\right)
$$

Angle of friction,

$$
\theta=\tan ^{-1} \mu
$$

where $\mu=$ co-efficient of friction, assumed 0.14 .

Hence for self-locking to be possible, $\alpha<\theta$.

Torque required to raise the load can be calculated as

$$
T=\frac{W d_{m}}{2} \tan (\theta+\alpha)
$$

The pitch of bevel gears is measured at the large end of the tooth. It should be noted that the clearance is uniform. $[14,15]$

The pitch angles are defined by the pitch cones meeting at the apex as shown in Fig. 9.

The pitch angles are related to the tooth numbers as follows

$$
\tan \alpha_{p}=\frac{N_{p}}{N_{g}}
$$

and

$$
\tan \alpha_{g}=\frac{N_{g}}{N_{p}}
$$


where $\alpha_{p}=$ Pinion pitch angles, $\alpha_{g}=$ Gear pitch angles, $N_{p}=$ Pinion tooth number, $N_{g}=$ Gear tooth number.

Gear ratio, therefore

$$
m^{c}=\frac{N_{g}}{N_{p}} .
$$

The input speed $\left(\mathrm{N}_{1}\right)$ to the gear drive from the handle was obtained using the relation:

$$
\frac{T_{2}}{T_{1}}=\frac{N_{1}}{N_{2}}=G \cdot R .
$$

where $\mathrm{T}_{2}=$ Output torque $(\mathrm{Nm}), \mathrm{T}_{1}=$ Input torque $(\mathrm{Nm}), \mathrm{N}_{1}=$ Input speed $(\mathrm{rpm}), \mathrm{N}_{2}=$ Output speed (rpm), G.R. = Gear Ratio.

The output speed $\left(\mathrm{N}_{2}\right)$ in equation 24 was obtained using the relation:

$$
N_{2}=2 \times N_{M N 3}
$$

where $\mathrm{N}_{\mathrm{IM} 3}=$ Average speed imposed by an operator on the jack handle.

The output torque $\left(\mathrm{T}_{2}\right)$ in equation 24 was also obtained using the relation:

$$
T_{2}=\frac{\text { Load }(\text { force exerted by crank disc pinion })}{M \cdot A .} \times r_{p}
$$

where $r_{p}=$ Radius of crank disc pinion circular path profile, M.A. = Mechanical advantage obtained from equation.

The input torque $\left(\mathrm{T}_{1}\right)$ was dependent on one of the objectives of the study which required the reduction of the effort (energy) applied to lift an object by an operator by at least $50 \%$. According to R.S. Khumi [3], torque may be defined as the product of force and the perpendicular distance of its line of action from the given point or axis.

Hence, this force was obtained from the effort applied at the handle which drives the shaft which in turn drives the driver bevel gear.

The effort on the handle was obtained using the relation:

$$
E_{1}=\frac{E_{\text {IN3 }}}{2}
$$

where $\mathrm{E}_{\mathrm{IM} 3}=$ Measured effort applied by an operator on the lifting jack handle.

Thus, Input torque $\left(\mathrm{T}_{1}\right)$ :

$$
T_{1}=E_{1} \times d_{1}
$$

Where $\mathrm{d}_{1}=$ Perpendicular distance between effort line of action on handle and input shaft.

\section{System Performance}

Let Torque (T) on shafts 1, 2, 3, 4, 5, 6, 7 and 8 represent T1, T2, T3, T4, T5, T6, T7 and T8 respectively. Then, the gears in the gear drive equal: $\mathrm{P}, \mathrm{Q}, \mathrm{R}, \mathrm{S}, \mathrm{M}, \mathrm{N}, \mathrm{O}, \mathrm{A}, \mathrm{B}, \mathrm{C}, \mathrm{D}, \mathrm{E}$, and F as shown in Fig 3a. The rotary motion of the handle is transmitted to the driver gear $\mathrm{P}$ through the input shaft 1.Gear P meshes with gear $\mathrm{M}$. Attached to gear $\mathrm{M}$ is gear $\mathrm{Q}$ which meshes with gear $\mathrm{N}$. Gear R meshes with gear O and gear S is attached to gear O. Gear S meshes with an idler gear A which in turn meshes with gear D. Gear D was attached to gear B which meshes with gear E. Gear $C$ was attached to gear E and meshes with gear F through the output shaft 8 . The motion of gear 8 rotates the crank disc about the axis of the output shaft 8 . 


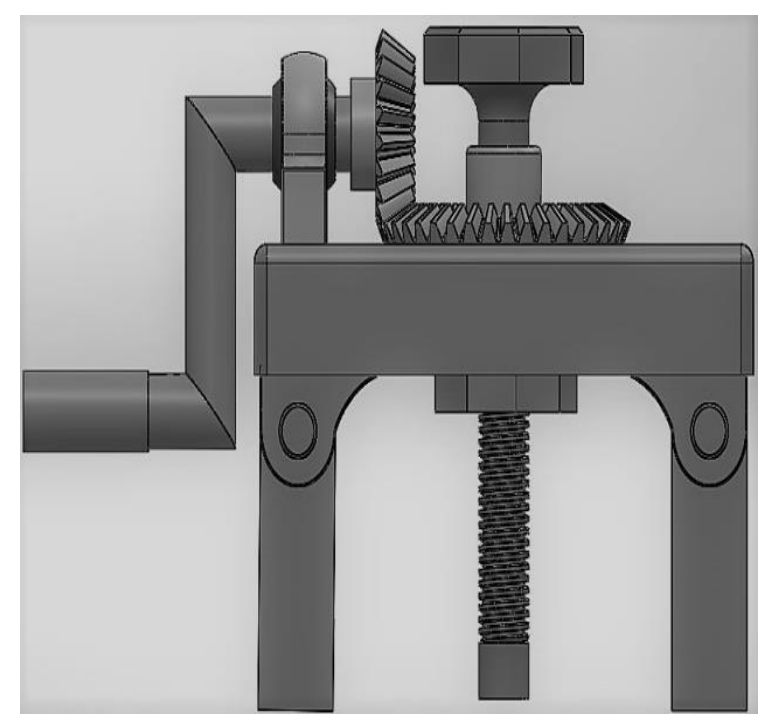

Figure 12. Side view of the jack.

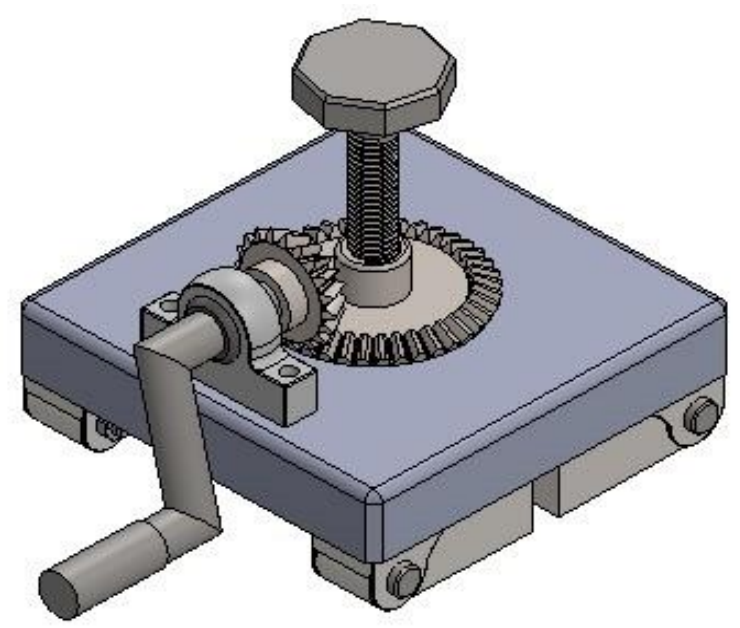

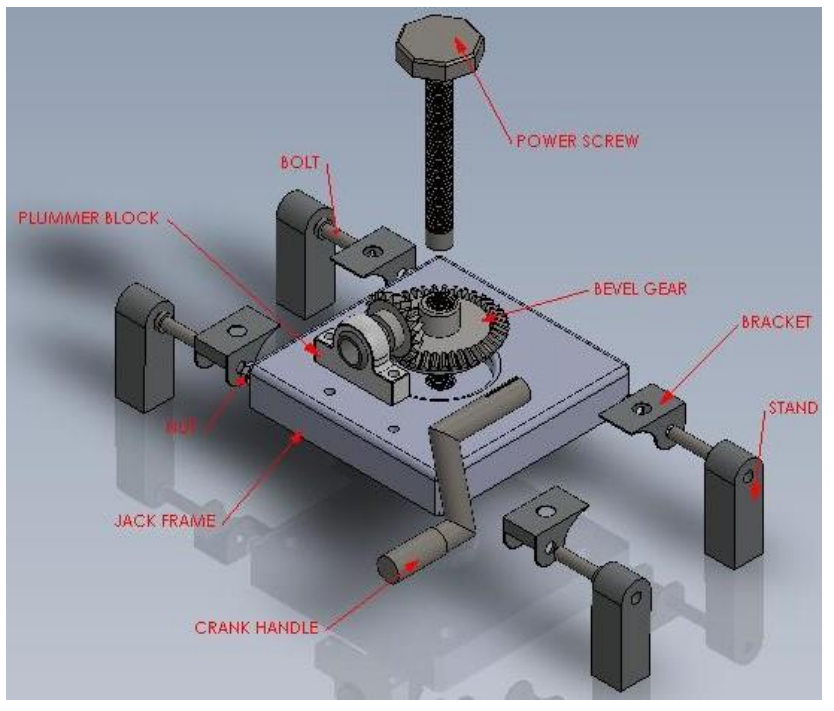

Figure 13. Exploded view of the jack.

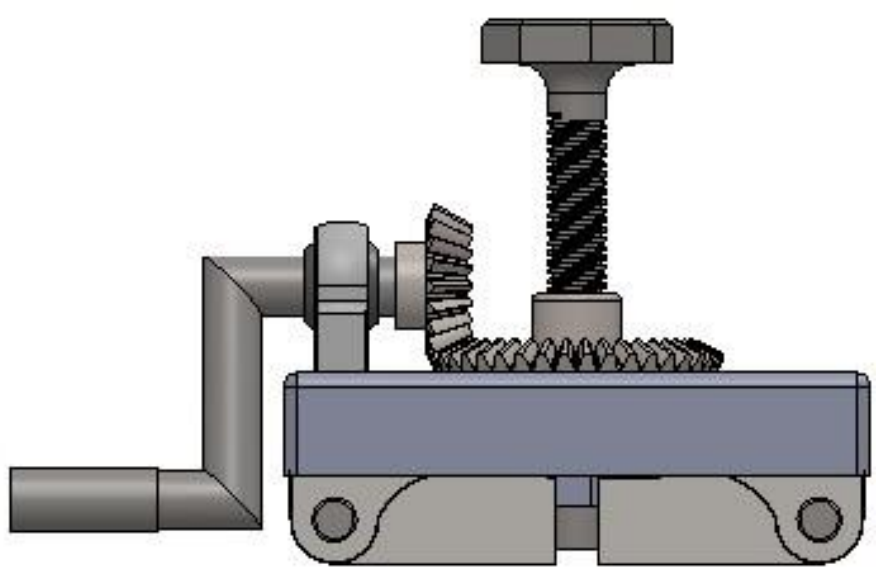

Figure 14. Pictorial view of the jack when folded.

Table 1. Gear Ratio relationship between gears in gear drive.

\begin{tabular}{|c|c|c|}
\hline Gear & Number of Teeth & Gear Ratio \\
\hline P;M & $6 ; 18$ & $3: 1$ \\
\hline Q;N & $6 ; 18$ & $3: 1$ \\
\hline R;O & $9 ; 18$ & $2: 1$ \\
\hline ; $\mathrm{A}$ & $10 ; 51$ & $5.1: 1$ \\
\hline A;D & $51 ; 15$ & $1: 3.4$ \\
\hline B;E & $51 ; 15$ & $1: 3.4$ \\
\hline C;F & $51 ; 15$ & $1: 3.4$ \\
\hline
\end{tabular}

\subsection{Analysis of Previous Design against Modified Design}

It requires far lesser time to lift an object compared to the lever powered system hence $50 \%$ queue reduction at service stations. See Table 2 and 3.

Table 2. Time Relationship between Lever Lift and Quick-return Crank Lift System.

\begin{tabular}{|l|c|c|}
\hline \multicolumn{1}{|c|}{ System } & Time (seconds) required to lift a car & Capacity (kg/m) \\
\hline Lever Lift System & 4.094 & 106.5 \\
\hline Quick-return crank Lift System & 2.025 & 152.8 \\
\hline
\end{tabular}


Table 3. Effort and Torque Relationship between Lever Lift and Quick-return Crank Lift System.

\begin{tabular}{|l|c|c|}
\hline \multicolumn{1}{|c|}{ System } & $\begin{array}{c}\text { Static force required to lift } \\
\text { a load in Newton }(\mathbf{N})\end{array}$ & $\begin{array}{c}\text { Torque required to lift } \\
\text { a load }(\mathbf{N m})\end{array}$ \\
\hline Lever Lift System & 127.400 & 135.04 \\
\hline Quick-return crank Lift System & Min: 5.280 & Min: 0.597 \\
& Max: 102.76 & Max: 51.38 \\
\hline
\end{tabular}

\section{Conclusion}

In this research, a novel design for a lifting jack driven by a quick-return crank mechanism and gear drive has been designed and fabricated. The design equations for gear selection, gear drive ratios and mechanism forces have been derived from its geometry. Kinematic analysis has been performed. A design example has been given for illustrating the design process. The detailed working diagram has been explicitly explained equally. To verify the feasibility and accuracy, a prototype has been made, and then an experiment has been conducted. The proposed mechanism is capable of increasing capacity; reducing input effort; saving cost of operation and requires simple maintenance compared to conventional lever lift mechanisms of lifting jacks. The experimental result shows that Very little effort $(5.280 \mathrm{~N}$ minimum and $102.76 \mathrm{~N}$ maximum) and torque $(0.597 \mathrm{Nm}$ and $51.38 \mathrm{Nm}$ maximum) is required to lift a load using the modified screw jack compared with the classical method which requires effort of $127.4 \mathrm{~N}$ and torque of $135.04 \mathrm{Nm}$. Also, the time required to lift a car using the modified method is lesser $(2.025 \mathrm{~s})$ compared to the time required to lift same weight of car using the traditional method (4.094s). Conclusively, the modified design provides a good alternative to the lever lift mechanism as other existing conventional lifting jacks require more effort, capacity, power generating sources and maintenance cost. The proposed quick lifting jack prototype was made up of a gear drive and a quick-return crank mechanism.

\section{References}

[1] A.S. Akinwonmi, A. Mohammed, Modification of the existing design of a car jack, Journal of Emerging Trends in Engineering and Applied Sciences. 3(4) (2012) 581-588.

[2] R.G. Budynas, J.K. Nisbett, Mechanical engineering design and advanced strength and applied stress analysis, McGraw-Hill, Vol. 10, 2008, pp. 925-1055.

[3] R.S. Khurmi, J.K. Gupta, Textbook of Machine Design, Eurasia Publishing House, Ram Nagar, New Delhi, India, 2005.

[4] I.S. Rout et al., Design and fabrication of motorized automated object lifting jack, IOSR Journal of Engineering. 04(05) (2014) 6-12.

[5] K.R. Mounika, C.H. Priyanka, Design and fabrication of motorized screw jack for four wheeler, A Project Report, Department of Mechanical Engineering, Gokaraju Rangaraju Institute of Engineering and Technology, 2011.

[6] C.A. Okoronkwo et al., Design of a hand water pump using a quick-return crank mechanism, African Journal of Science, Technology, Innovation and Development. 8(3) (2016) 292-298.

[7] S. Chaudhary et al., Development of motorized car jack, Journal of Applied Mechanical Engineering. 5 (2016) 216.

[8] M.N. Kumar et al., Design and fabrication of screw jack using worm gear, International Conference on Systems, Science, Control, Communication, Engineering and Technology, 2016, pp. 794-798.

[9] R.K. Rajput, A textbook of engineering thermodynamics, Firewall Media, 2010. 
[10] M.A. Parker, F. Pickup, Engineering drawing with worked examples, Third Edition, Vol. 1, Hutchinson, New Delhi, 1976, pp. 690-699.

[11] J.M. Gere, Mechanics of materials, Thomson, 6th Edition, 2006.

[12] R.K. Rajput, Thermal engineering, Laxmi Publications, 2010. ISBN: 8131808041.

[13] C.W. Ham, D.G. Ryan, Experimental investigation of the friction of screw threads, Bulletin 247, University of Illinois at Urbana Champaign, College of Engineering, Engineering Experiment Station, 1932.

[14] R.G. Budynas, J.K. Nisbett, Shidley’s mechanical engineering design, McGraw-Hill Education, New York, 2011.

[15] S.R. Patel, D.S. Patel, Dynamic analysis of quick return mechanism using MATLAB, International Journal of Engineering Science and Innovative Technology. 2(3) (2013) 346-350. 